\title{
The Yield-Point Phenomenon and Cyclic Plasticity of the Console Beam
}

\author{
Andrej Žerovnik* - Ivan Prebil - Robert Kunc \\ University of Ljubljana, Faculty of Mechanical Engineering, Slovenia
}

In the paper, the influence of the yield-point phenomenon (YPP) on cyclic plasticity of the console beam is presented with the objective to demonstrate the impact of the YPP on the local cyclic plasticity. The influence of the YPP and its dependence on cyclic material hardening or softening was studied through experiments and numerical simulations. Console beams are made from the low-alloy EN $42 \mathrm{CrMo} 4$ steel in its normalized state (184 HV), which exhibits cyclic hardening, and in its tempered state (296 HV), which is subject to cyclic softening. Numerical simulations were performed on constitutive model of cyclic plasticity taking into account the kinematic hardening, isotropic hardening or softening and formulations of the YPP which are based on the change of the elastic region surface in the stress space at first transition into the stress plateau. Analysis of the results shows the importance of taking into account the YPP equations in constitutive models of cyclic plasticity as well as the influence of the YPP on cyclic plasticity of the console beam.

Keywords: yield-point phenomenon, cyclic plasticity, mechanical testing, FEM simulations

Highlights

- $\quad$ The yield-point phenomenon (YPP) was observed in relation with cyclic plasticity of the console beam.

- $\quad$ The influence of the YPP on cyclic plasticity of the console beam was determined from experimental and numerical simulations of cyclic bend tests.

- $\quad$ Research was made with the objective to demonstrate the impact of the YPP on the local cyclic plasticity.

- $\quad$ Based on the presented results, it is evident that formulation of the YPP in constitutive models of cyclic plasticity leads to more realistic results of cyclic plasticity.

\section{INTRODUCTION}

The yield-point phenomenon (YPP) is the result of a rapid increase in the number of mobile dislocations [1] and [2] and is common in iron [3], low-alloy steels [4] and [5], titanium alloys [6], aluminium [7] and [8], tantalum [9] and [10] and several other metallic alloys [11] to [14] as well as in composites and laminates [15] and [16], polymers [17] and [18] and even rocks [19] and [20].

Most previous studies that were engaged with the influence of the YPP analyse the reasons behind its development and its effects on monotonic loading [1], [2] and [5]. The stress state and the reasons associated with Lüders banding were researched by Schwab and Ruff [21]. Barnett et al. [14] made a major step by experimental microstructural analysis for verification of the onset of deformation twinning in Lüders bands. Wenman and Chard-Tuckey [22] analyse the effect of the Lüders strains on residual stresses from various material hardening models in uniaxially-loaded specimens. The effect of Lüders bands on the bending of steel tubes was discussed by Aguirre et al. [23], Hallai and Kyriakides [24] and Bechle and Kyriakides [6]. Recently, Zou et al. [25] observed cyclic loading in yield plateau and Žerovnik et al. [26] presented the influence of the YPP on cyclic plasticity of the uniaxially loaded specimens.

The first to describe the uniaxial model of the YPP was Hahn [27]. The presented model described the stress drop based on Johnston and Gilman's [28] concept of a rapid increase in the number of mobile dislocations at the yield point. Shioya and Shioiri [29] later expanded Hahn's model to a multiaxial one, while Itoh et al. [30] was the first to implement Hahn's model to the finite-element code.

Cyclic plasticity research has a long and rich tradition. Armstrong and Frederick [31] were among the first to describe kinematic hardening. Their work was later extended by Chaboche et al. [32] and Chaboche [33] and [34], whose proposal included a superposition of three kinematic rules. Mostly with a view to further improve ratcheting simulation, several other models were later proposed [32], [35] to [41]. Chaboche [42] presented a comprehensive overview of the selected constitutive models. Particularly worth mentioning is the Ohno-Wang model [43] and [44], which introduced critical state of dynamic recovery into kinematic hardening rules. Although of a slightly earlier date, the Ohno-Wang model had not lost its relevance, as was confirmed by $\mathrm{Yu}$ et al. [40] in their upgraded model integrating equations of cyclic viscoplasticity. Similarly, the Ohno-Wang model was also 
modified by Abdel-Karim [39], who proved that inclusion of isotropic hardening enabled the model to predict uniaxial as well as multiaxial ratcheting. Another interesting model that related cyclic hardening to the plastic strain history was proposed by Korelc et al. [45].

However, only few research studies [26], [46] to [48] are focused on the effect of the YPP in combination with cyclic plasticity. Even the materials which express the YPP was addressed by constitutive models of cyclic plasticity, the YPP is not taken into account in most of those models. [49] to [51]. In most cyclic load cases, the zone of elastic deformation surrounds the plastic deformation zone, and failure to consider the YPP would lead to incorrect predictions of plastic deformation deviating from the real-life situation. In order to conduct precise stress-strain analyses, a constitutive model is needed which enables accurate descriptions of the YPP as well as subsequent cyclic plasticity. In the recent period, Yoshida [47] and [48] has made a significant contribution in this field. He has presented two ratedependent models of cyclic plasticity, which describe kinematic and isotropic hardening as well as the YPP. In his model based on the micromechanical approach, Yoshida claims that after the yield point an abrupt yield drop takes place because of the rapid multiplication of dislocations. Besides describing the phenomenon, Yoshida also used the benefits of the YPP for solving real-world problems [47]. Žerovnik et al. [46] presented their observations of the YPP based on the phenomenological approach which relates the yield plateau with a reduction in the size of the elastic region surface and displacement of the elastic region centre in the stress space.

The aim of this paper is to present and evaluate the influence of the YPP on cyclic plasticity behavior of the console beam, with the objective to demonstrate the impact of the YPP on the local cyclic plasticity. The study is based on a combination of experimental observations and numerical simulations.

\section{EXPERIMENTAL OBSERVATIONS}

The influence of the YPP on cyclic plasticity was estimated from cyclic bend tests of console beams (Fig. 1). Console beams were made from low-alloy EN 42 CrMo 4 steel, which exhibits cyclic hardening in its normalized state and cyclic softening in its tempered state [26]. To analyse the impact of the YPP in combination with cyclic hardening or softening, console beams were prepare in two different states, normalized (184 HV) and hardened (296 HV).
The experiments were conducted on the Instron 8802 test rig [52]. An additional clamping device was made for the purpose of attaching the specimens (Fig. 2). The stiffness of the clamping device was verified through numerical stress-strain simulations, which showed that the impact of the clamping device strains on console beam displacement is less than $1 \%$ of the measured value in all predicted load cases. Instron 2527-101 dynamic load cell (capacity $\pm 250 \mathrm{kN}$ and certified measurement system error $\pm 0.1 \%$ of total range) was used to measure the force applied to the beam and the console beam displacement was measured using Instron 2620-604 Dynamic Extensometer (gauge length of $15 \mathrm{~mm}$ and certified measurement system error $\pm 0.1 \%$ of total travel) (Fig. 2). Symmetric and asymmetric cyclic bend tests were performed under displacement control (Table 1) at a loading frequency of $0.5 \mathrm{~Hz}$ and under time-dependent sinusoidal load.

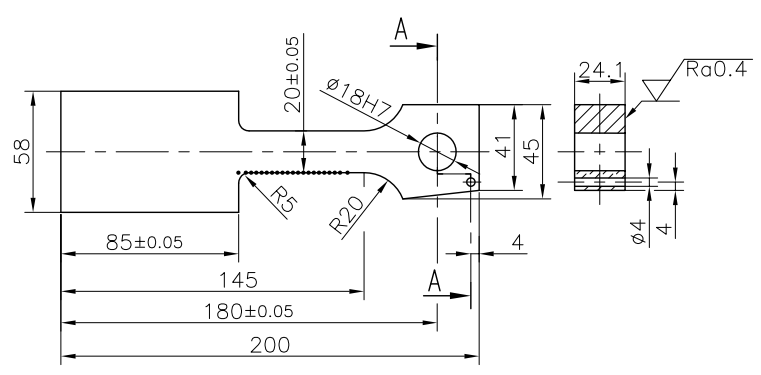

Fig. 1. A console beam

Table 1. Cyclic bend experiments of console beams

\begin{tabular}{ccc}
\hline Specimen & Displacement amplitude [mm] & Heat treatment \\
\cline { 1 - 2 } CN1 & 2 & \\
CN2 & 3 & $\begin{array}{c}\text { Normalized } \\
(184 \mathrm{HV})\end{array}$ \\
\hline CN3 & 4 & \\
\hline CN4 & $2^{*}$ & Tempered \\
\cline { 1 - 1 } CT1 & 3 & $(296 \mathrm{HV})$ \\
\hline CT2 & 4 & \\
* Asymmetric loading, mean displacement value is $2 \mathrm{~mm}$.
\end{tabular}

During cyclic loading of the console beams made of $184 \mathrm{HV}$ steel, the GOM Aramis 5M measurement system was used to observe the strain field of the specimens (Fig. 2). Optical measurement system has lenses with a focal point of $50 \mathrm{~mm}$, the area of image capture was $35 \mathrm{~mm} \times 29 \mathrm{~mm}$. System resolution at 0.032 pixels and system error at 0.06 pixels is automatically evaluated. 

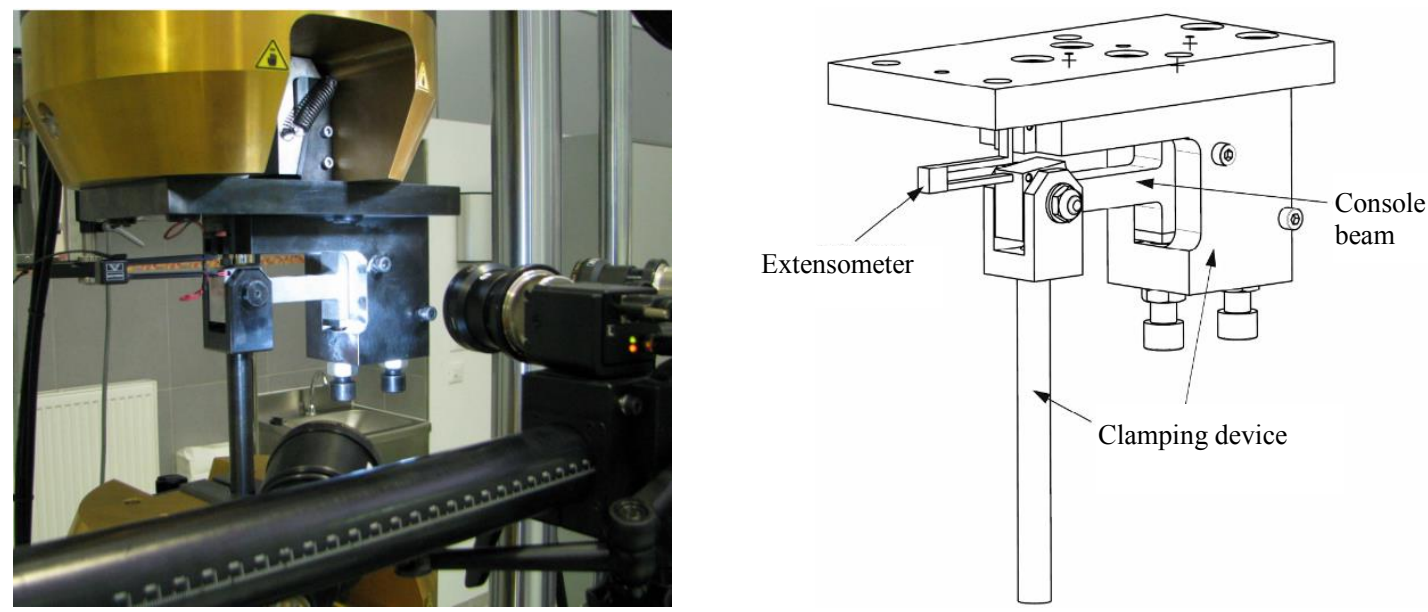

Fig. 2. Cyclic loading of a console beam

\section{NUMERICAL SIMULATIONS}

A source code for a three-dimensional eight-node isoparametric finite element was generated for FEM-based numerical simulations. The formulation was based on the displacement field method, and the stiffness matrix was derived with the variation approach [46]. The FE code was generated using the symbolic algebra package AceGen [53]. Additionally, FE models of a console beam were built (Fig. 3).

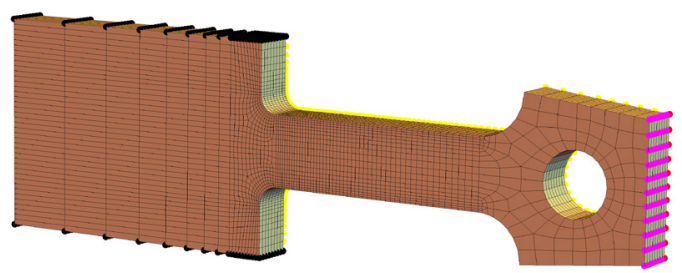

Fig. 3. FE model of a console beam loaded in bending

The constitutive model integrated in the FE code is based on the phenomenological approach and the small-strain theory. The isotropic material properties are assumed. The model includes descriptions of material cyclic hardening or softening, nonlinear kinematic hardening, and the YPP. Also, it takes into account the von Mises yield surface, whereas the equation defining the size of the yield surface $F$ is supplemented by coefficients of the YPP as well as cyclic and kinematic hardening [46]:

$$
F=\tilde{\sigma}_{e q}-\left(R-M+\sigma_{\text {Ypre }}\right)+\sigma_{\text {Ycor }}=0,
$$

where $\sigma_{Y p r e}$ stands for the stress of the upper yield point and $R$ for the coefficient of cyclic hardening or softening. $M$ is the coefficient of the YPP which denotes the isotropic changing of the elastic region size within the stress space resulting from an increase in the number of mobile dislocations at transition from the elastic into the elasto-plastic region. $\sigma_{Y c o r}$ is the yield stress correction expressing the change in the size of the elastic region within the yield region. $\tilde{\sigma}_{e q}$ denotes equivalent stress [46].

The shift in the position of the elastic domain in the stress space (i.e. the Bauschinger effect) is given by the evolution equation for the back stress describing kinematic hardening, which was originally proposed by Armstrong and Frederick [31] and later extended by Chaboche [33]:

$$
\mathbf{X}=\sum_{n=1}^{3} \mathbf{X}^{(n)}
$$

The segments of the kinematic curve $(n=1,2,3)$ are described by an equation proposed by Ohno and Wang [43] and [44], which takes into account the Bauschinger effect and uses the Ohno-Wang parameters to consider mean-stress relaxation in the event of asymmetric hardening:

$$
\dot{\mathbf{X}}^{(n)}=\frac{2}{3} \gamma^{(n)} X_{\infty}^{(n)} \dot{\boldsymbol{\mu}}^{p}-\left(\frac{X_{e q}^{(n)}}{X_{\infty}^{(n)}}\right)^{m^{(n)}} \mathbf{X}^{(n)} \gamma^{(n)} \dot{\lambda} .
$$

The change in the elastic region size in the stress space is defined by the isotropic cyclic hardening or softening equation. Uniaxial experimental observations [26] show that material hardening or softening continues for the specimen's whole remaining life time. The rate of hardening also depends on the magnitude of the plastic strain. In his observations of cyclic plasticity in construction steels, Korelc [45] detected similar behavior and later 
described the isotropic cyclic material response with a cyclic hardening model that integrates the time history of plastic deformation:

$$
\dot{R}=b_{0}\left(b_{1} \cdot \lambda+R_{\infty}\left(\varepsilon_{p, \max }\right)-R\right) \dot{\lambda}+b_{1} \cdot \dot{\lambda},
$$

where:

$$
\begin{gathered}
b_{1}=\operatorname{sgn}\left(R_{\infty, s}\right) \cdot 1-e^{-s_{0} \cdot \varepsilon_{p, \max }}, \\
R_{\infty}=R_{\infty, s}\left(1+(\alpha-1) e^{-\xi \cdot \varepsilon_{p, \max }}\right) .
\end{gathered}
$$

Yoshida [47] and [48] was the first to point out that it is not sensible to consider cyclic hardening or softening in the region of Lüders bands $\left(\varepsilon_{L}\right)$.This applies only to the first transition from the elastic into the elasto-plastic region (monotonic loading), and not to subsequent cyclic loading in the Lüders strain region.

The YPP in Eq. (1) is described by $M$ and $\sigma_{Y c o r}$. The stress drop after the upper yield point is described by the equation denoting the isotropic changing of the elastic region size [46]:

$$
\dot{M}=c\left(\sigma_{\text {Ydrop }}-M\right) \dot{\lambda} \text {. }
$$

The correction of yield stress which describes the change of the elastic region size in the stress plateau and is taken account of in the yield Eq. (1) is as follows [46]:

$$
\sigma_{\text {Ycor }}= \begin{cases}X_{e q} & \text { for stress plateau } \\ & \text { region, } \\ \sigma_{Y p r e}-\sigma_{\text {Ypost }}-\sigma_{\text {Ydrop }} & \text { for strain } \\ \text { hardening region. }\end{cases}
$$

The constitutive model parameters for EN 42 CrMo 4 which were used in the implementation of numerical simulations are given by Table 2 .

\section{RESULTS AND DISCUSSION}

The results of the analyses of cyclic plasticity of console beams will be presented in this paper to provide a clearer picture of the influence which the YPP has on cyclic plasticity of the structural elements, where local cyclic plasticity occurs.

Numerical simulations were conducted for two model cases: firstly, for the constitutive model which includes YPP descriptions (with the YPP), and secondly, for the constitutive model not taking account of the YPP (without the YPP).
Table 2. EN 42 CrMo 4 material parameters of the constitutive model

\begin{tabular}{lccc}
\hline Parameter & Unit & $\begin{array}{c}\text { Normalized } \\
(184 \mathrm{HV})\end{array}$ & $\begin{array}{c}\text { Tempered } \\
(296 \mathrm{HV})\end{array}$ \\
\hline$E$ & $\mathrm{~N} / \mathrm{mm}^{2}$ & 203020 & 198085 \\
\hline$v$ & - & 0.3 & 0.3 \\
\hline$c$ & - & 2800 & 1800 \\
\hline$\varepsilon_{L}$ & - & 0.007 & 0.01 \\
\hline$\sigma_{\text {Ypre }}$ & $\mathrm{N} / \mathrm{mm}^{2}$ & 410 & 850 \\
\hline$\sigma_{\text {Ypost }}$ & $\mathrm{N} / \mathrm{mm}^{2}$ & 180 & 520 \\
\hline$\sigma_{\text {Ydrop }}$ & $\mathrm{N} / \mathrm{mm}^{2}$ & 40 & 28 \\
\hline$B_{0}$ & - & 35 & 10 \\
\hline$R_{\infty, s}$ & $\mathrm{~N} / \mathrm{mm}^{2}$ & 65 & -195 \\
\hline$S_{0}$ & - & 155 & 92 \\
\hline$\alpha$ & - & 0.02 & 0.9 \\
\hline$\zeta$ & - & 105 & 155 \\
\hline$\gamma_{1}$ & - & 3200 & 549 \\
\hline$\gamma_{2}$ & - & 600 & 103 \\
\hline$\gamma_{3}$ & - & 27 & 40 \\
\hline$X_{\infty}$ & $\mathrm{N} / \mathrm{mm}^{2}$ & 50 & 245 \\
\hline$X_{\infty}{ }_{\infty}$ & $\mathrm{N} / \mathrm{mm}^{2}$ & 75 & 157 \\
\hline$X_{\infty}$ & $\mathrm{N} / \mathrm{mm}^{2}$ & 400 & 180 \\
\hline$m^{1}$ & - & 5 & 2 \\
\hline$m^{1}$ & - & 5 & 1.5 \\
\hline$m^{1}$ & - & 1.5 & 0.8 \\
\hline & & & \\
\hline & - & 50 & \\
\hline
\end{tabular}

Formulation and material parameters of the constitutive model for isotropic hardening/softening and kinematic hardening are the same in both cases. The results obtained from numerical simulations were compared against experimental data. In terms of the stress-strain curves of uniaxial tensile-compression loads [26], the difference between the two models (model with the YPP and model without the YPP) only exists in the first cycle, where transition from the elastic into the elasto-plastic region occurs at different yield stress. The model with the YPP is consistent with the experimental results, whereas the model without the YPP in the first cycle at transition into plastic strain does not follow the experimental results. Fig. 4. shows the comparison between different shapes of the stress-strain curve exhibited by the uniaxially cyclically loaded specimens.

The following part of the paper presents the impact of the YPP formulation on the results of numerical simulations of the cyclically loaded console beam in bending. Due to long computation times, numerical simulations for all load cases of cyclic plasticity of console beams were performed for the first 100 cycles. In view of their high number, the results of certain load cases which showed similar effects or benefits are not presented. 


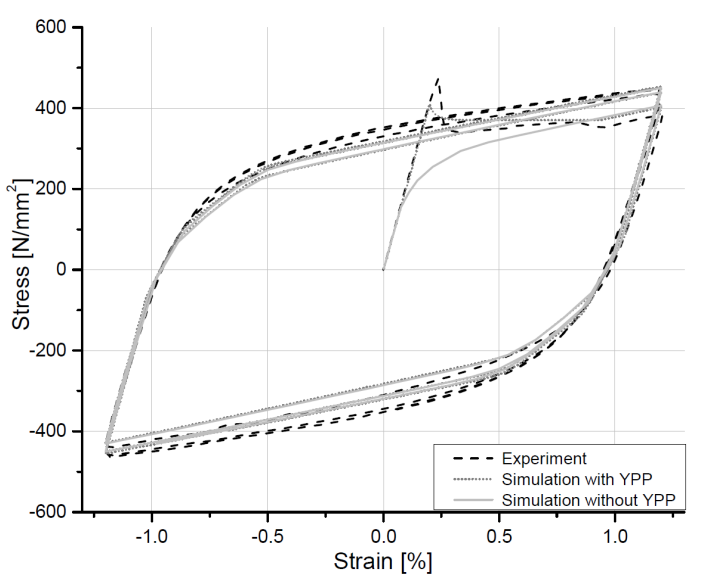

Fig. 4. Comparison of stress-strain hysteresis loops under uniaxial tensile-compression cyclic loading, strain amplitude $\Delta \varepsilon=1.2 \%$, for models with and without the YPP (184 HV)

Figs. 5, 6, 9 and 10 show a comparison of forcedisplacement hysteresis loops for the first and second cycles and the force and displacement amplitudes in relation to the number of cycles for the $184 \mathrm{HV}$ material, while Fig. 11 illustrates the flow of force amplitudes relative to the number of cycles for the 296 HV material.

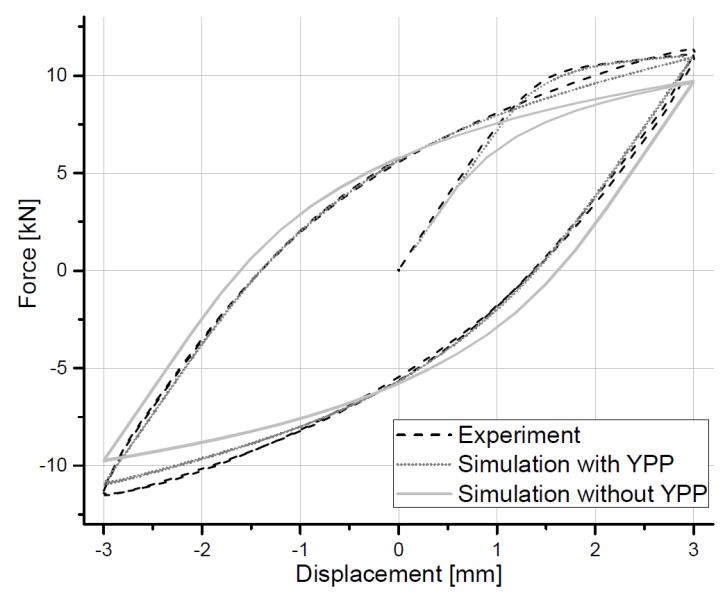

Fig. 5. Comparison of force-displacement hysteresis loops for the 1st and 2nd cycle at a displacement amplitude of $3 \mathrm{~mm}, 184 \mathrm{HV}$ material

Fig. 5 shows force-displacement hysteresis loops for the first and second cycle, under cyclic loading at a displacement amplitude of $3 \mathrm{~mm}$. The figure demonstrates very good agreement between the experimental and numerical results for models including the YPP, whereas simulation results deviate across the entire loaded region if the YPP is not considered in the constitutive model. These deviations are most expressed in the shape of the first cycle hysteresis loop. When the YPP is not taken into account, the force-displacement curve transits from the linear into the nonlinear region at a force of $4 \mathrm{kN}$; otherwise, this transition takes place at $8.5 \mathrm{kN}$.

A similar trend is evident in the comparison of force amplitudes and the number of cycles (Fig. 6). In simulations with the YPP, numerically-obtained force amplitude results deviate from experimental data by a maximum of $3 \%$ at a strain amplitude of $2 \mathrm{~mm}$, while in models without the YPP, the discrepancy between experimental and simulation results is between $6 \%$ and $20 \%$. It should also be noted that in models with the YPP the force amplitude curve (Fig. 6) is similar in shape across the entire region to the curves obtained from experiments. If the YPP is not taken into account, the shape of the curve deviates more significantly. A satisfactory agreement of numerical and experimental results is also revealed in load cases at a displacement amplitude of $3 \mathrm{~mm}$ (Fig. 6). Simulation-generated force amplitude curves taking account of the YPP only deviate from experimental results in the first 20 cycles, by a maximum of $4 \%$, while deviations between experimental and simulation results for cases where the phenomenon is not considered are between $4 \%$ and $15 \%$.

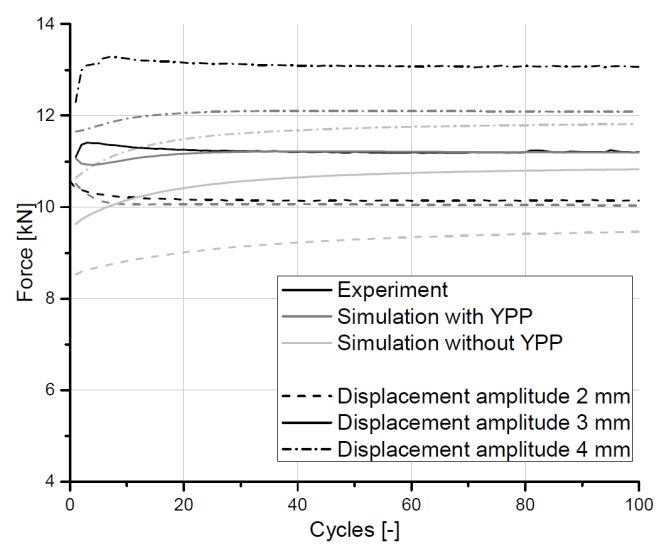

Fig. 6. Comparison of force amplitudes under cyclic loading at symmetric displacement amplitudes of 2, 3 and $4 \mathrm{~mm}, 184 \mathrm{HV}$ material

Slightly lower agreement between the model with the YPP and experiment becomes evident during loading at a displacement amplitude of $4 \mathrm{~mm}$ (Fig. 6). The discrepancy results from slightly changed characteristics of the specimen material which exhibits faster hardening in the cyclic strain region. This hypothesis is confirmed in Fig. 9, which indicates that the curves for experimental and simulation results that include the YPP show a good agreement during the first cycle up to the displacement of $4 \mathrm{~mm}$. 
It is interesting to observe and compare force amplitudes for symmetric load cases at displacement amplitudes of $2 \mathrm{~mm}$ and $4 \mathrm{~mm}$ (Fig. 6), since they show different force amplitude curves for experiment and simulation results if the YPP is considered. Symmetric load cases at a displacement amplitude of $2 \mathrm{~mm}$ display a drop in the force amplitude curve. Under symmetric loading at a displacement amplitude of $4 \mathrm{~mm}$ the force amplitude rises. The change in the softening or hardening trend is due to the prevalent influence of the YPP for the $2 \mathrm{~mm}$ displacement amplitude and the influence of isotropic cyclic hardening for the $4 \mathrm{~mm}$ displacement amplitude. This is evident in Figs. 7 and 8, which show the values of the isotropic hardening variable $(R)$ and the yield stress correction variable $\left(\sigma_{Y c o r}\right)$. The figures show the state of the console beam after the $1^{\text {st }}, 20^{\text {th }}, 50^{\text {th }}$ and $100^{\text {th }}$ cycle on the observed region, marked with a dotted line in Fig. 1. At a displacement amplitude of $2 \mathrm{~mm}$ (Fig. 7), the state of the material in the observed region during the first few cycles is within the stress plateau and consequently $\sigma_{Y c o r}$ increases. A significant increase occurs in the right part of the console beam (at a distance between $105 \mathrm{~mm}$ and $123 \mathrm{~mm})$. Similarly to $\sigma_{Y c o r}$, the isotropic hardening variable $(R)$ also increases during the cyclic loading. In the left part of the observed console beam field (at a distance between $85 \mathrm{~mm}$ and $105 \mathrm{~mm}$ from the left face), the change in variables $R$ and $\sigma_{Y c o r}$ is of the same magnitude, whereas in the right part (at a distance between 105 and $123 \mathrm{~mm}$ ) the change in variable $\sigma_{Y c o r}$ is more prominent, which consequently affects the force amplitude drop. The force drop is in relation with the nonhomogeneous material response in the first cycles when the strain amplitude is lower than Lüders strain [26]. In the event of a displacement amplitude of $4 \mathrm{~mm}$ (Fig. 8), in the observed region of the console beam plastic strain occurs during the first loading is bigger than the stress plateau (Fig. 12), due to which variable $\sigma_{Y c o r}$ reaches its limit value in the first cycle in the left part of the observed region of the console beam. Consequently, during further loading variable $\sigma_{Y c o r}$ changes only in the right part of the observed region of the console beam. Since deformations in this load case are significantly bigger than in the event of loading at a displacement amplitude of $2 \mathrm{~mm}$, the value of the isotropic loading variable $R$ is also bigger. It is prominent in the left part of the observed region of the console beam and consequently leads to force amplitude growth during cyclic loading.

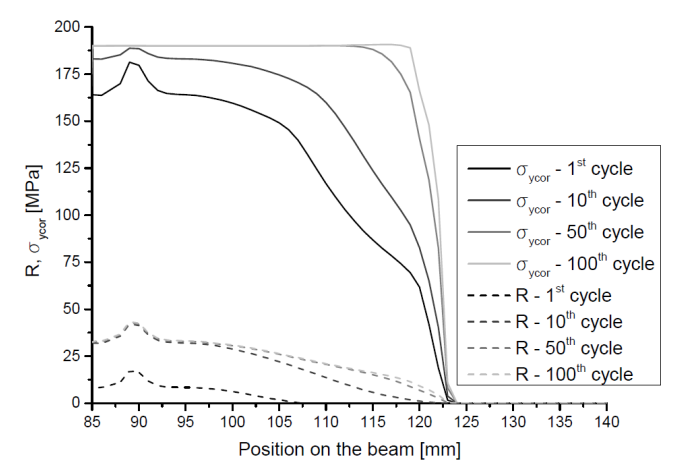

Fig. 7. Values of variables $R$ and $\sigma_{Y c o r}$ under symmetric loading at a strain amplitude of $2 \mathrm{~mm}$

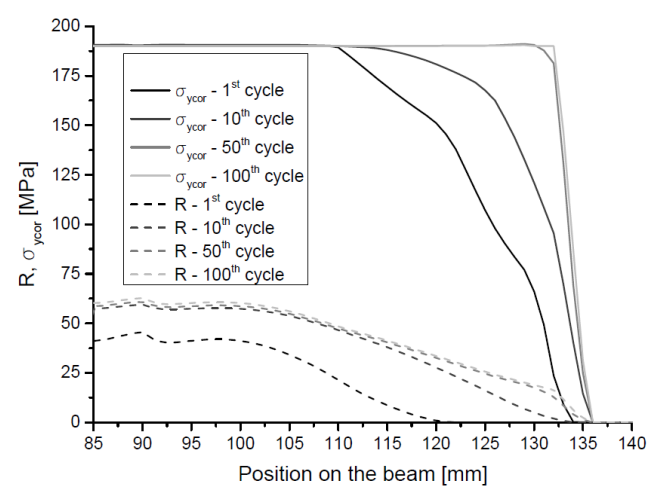

Fig. 8. Values of variables $R$ and $\sigma_{Y c o r}$ under symmetric loading at a strain amplitude of $4 \mathrm{~mm}$

In numerical simulations without the YPP, the force amplitude curve constantly increases and does not correspond with experimental data (Fig. 6).

Even in displacement-controlled asymmetric load cases (Figs. 9 and 10), numerical simulation results show a better agreement with experimental results when the YPP is taken into account.

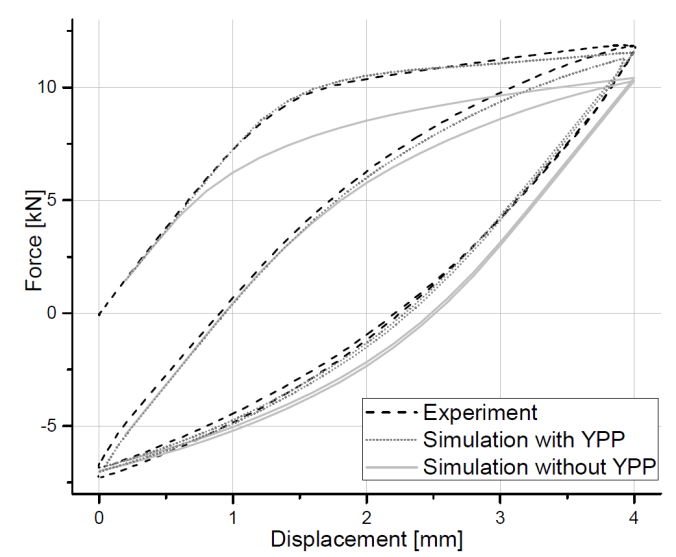

Fig. 9. Comparison of force-displacement hysteresis loops for the $1^{\text {st }}$ and $2^{\text {nd }}$ cycle under asymmetric loading at a displacement amplitude of $2 \mathrm{~mm}$ and mean value of $2 \mathrm{~mm}, 184 \mathrm{HV}$ material 


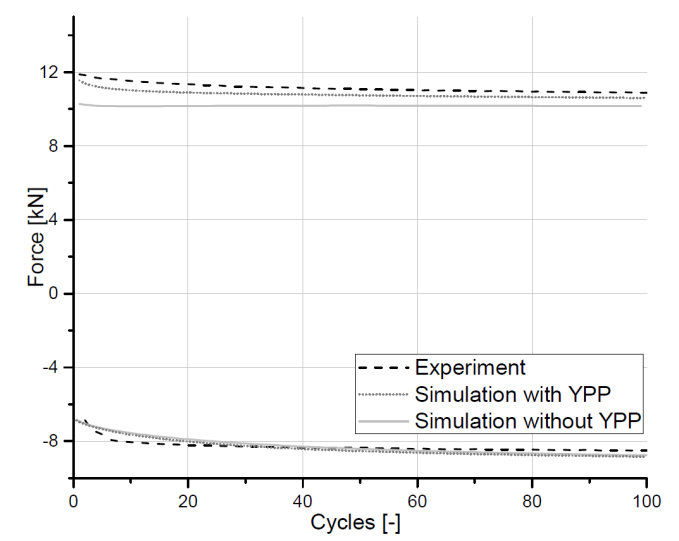

Fig. 10. Comparison of force amplitudes under asymmetric cyclic loading at a displacement amplitude of $2 \mathrm{~mm}$ and mean value of 2 $\mathrm{mm}, 184 \mathrm{HV}$ material

Console beams made from the $296 \mathrm{HV}$ material were subjected to cyclic plasticity in order to analyse the influence of the YPP in correlation with cyclic softening. Fig. 11 gives a comparison of force amplitudes in relation to the number of cycles for a displacement amplitude of $4 \mathrm{~mm}$. Experimental results are in good agreement with numerical simulations for the cases including the YPP, and differ by approximately up to $20 \%$ for cases without the YPP.

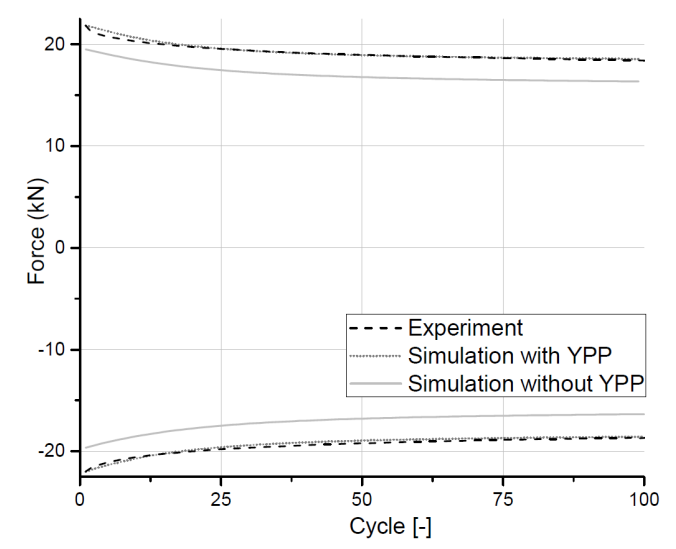

Fig. 11. Comparison of force amplitudes under cyclic loading at a symmetric displacement amplitude of $4 \mathrm{~mm}, 296 \mathrm{HV}$ material

A strain-field comparison is another way to assess the benefit of describing the YPP. Fig. 12 shows a comparison of the von Mises equivalent strain for a displacement amplitude of $4 \mathrm{~mm}$. Strain fields are given for the $1^{\text {st }}$ and $100^{\text {th }}$ cycle. The entire strain of the console beam in the region of greatest deformation is given. As seen below, experimental results are in better agreement with numerical results when the YPP is taken into account, which further supports the merit of supplemented equations describing this phenomenon. The difference is particularly evident in the first cycle but dissipates slightly until the $100^{\text {th }}$ cycle due to cyclic hardening. The influence of the YPP in constitutive models of cyclic plasticity on the strain-stress state of a console beam is clearly expressed in the illustration of von Mises stresses in the beam. Figs. 13 and 14 show a comparison of the stresses in the $1^{\text {st }}$ and $100^{\text {th }}$ cycle for the material with hardness levels of $184 \mathrm{HV}$ and $296 \mathrm{HV}$ for a variety of load cases. The course of maximum von Mises stresses is completely different depending on whether or not the YPP is taken into account. For the $184 \mathrm{HV}$ beams, the maximum comparative stresses in cases considering the YPP amount to $410 \mathrm{~N} / \mathrm{mm}^{2}$ in the $1^{\text {st }}$ and $100^{\text {th }}$ cycle. If the YPP is not taken into account, these values are $181 \mathrm{~N} / \mathrm{mm}^{2}$ in the first or $230 \mathrm{~N} / \mathrm{mm}^{2}$ in the $100^{\text {th }}$ cycle (Fig. 13). The reason behind these differences lies in the inclusion of the YPP as it describes the changes in the size (i.e. reductions) of the elastic region at transition over the Lüders plateau. The growth of maximum comparative stresses in models without the YPP is attributable to cyclic material hardening. Fig. 14, which shows maximum comparative stresses for a $296 \mathrm{HV}$ beam, demonstrates a similar response. In this case, the

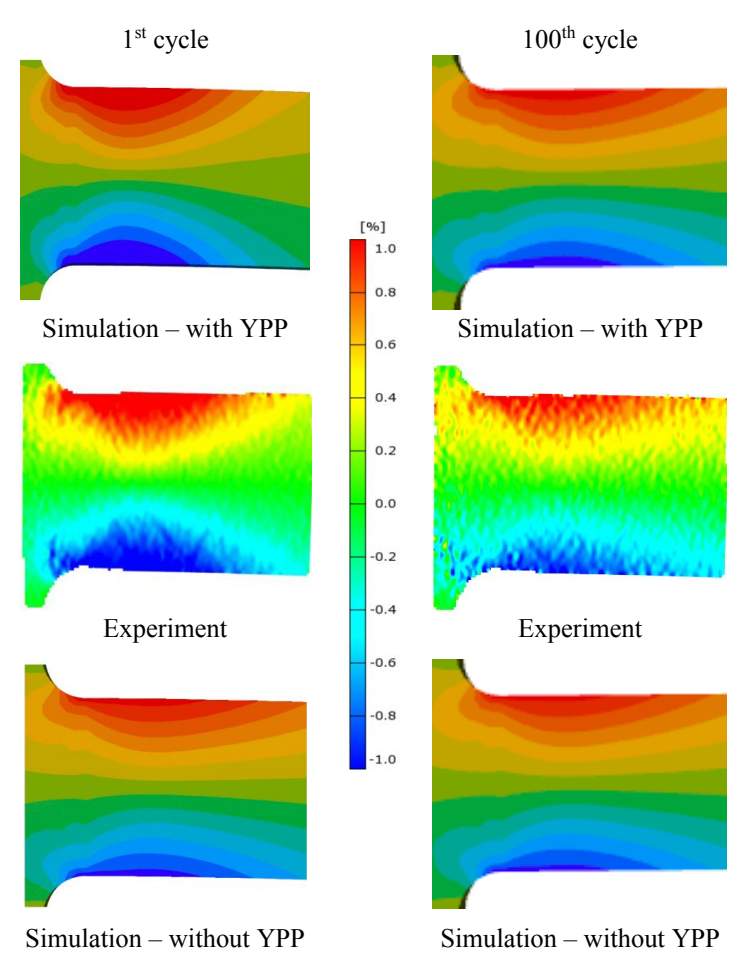

Fig. 12. Comparison of console beam strain fields for the $184 \mathrm{HV}$ material (symmetric loading, displacement amplitude of $4 \mathrm{~mm}$ ) 

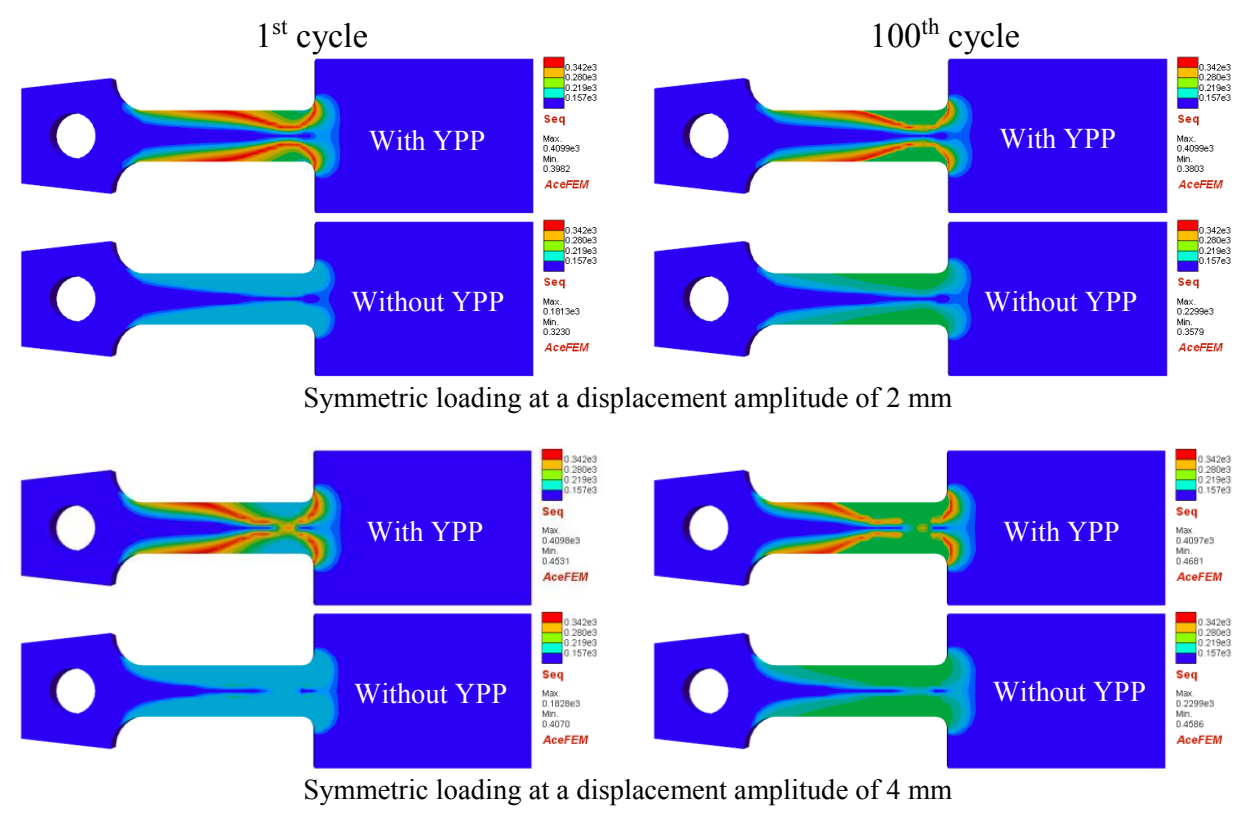

Fig. 13. Maximum von Mises stress in the 1 st and $100^{\text {th }} \mathrm{cycle}$, for models with and without the YPP, 184 HV material

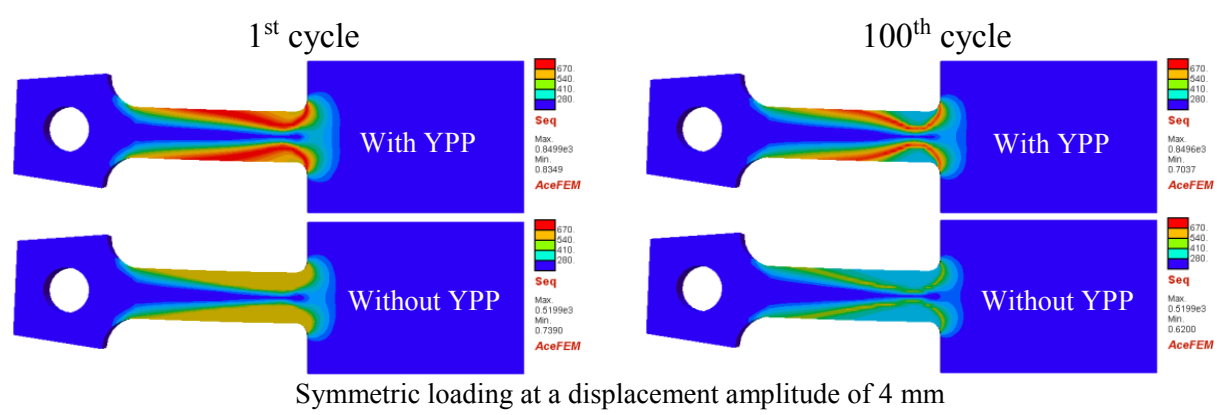

Fig. 14. Maximum von Mises stress in the $1^{\text {st }}$ and $100^{\text {th }}$ cycle, for models with and without the YPP, 296 HV material

maximum comparative stresses in the $1^{\text {st }}$ and $100^{\text {th }}$ cycle reach $850 \mathrm{~N} / \mathrm{mm}^{2}$ if the YPP is taken into account, and $520 \mathrm{~N} / \mathrm{mm}^{2}$ if it is not included, which is consistent with the model parameters given in Table 2.

Figs. 13 and 14 also point out the differences in the development of von Mises stresses during cyclic softening or hardening. In the $184 \mathrm{HV}$ materials exhibiting cyclic hardening, the plastic strain region expands (in particular at a displacement amplitude of $4 \mathrm{~mm}$ and with the YPP, as seen in Fig. 13) and the maximum stress region moves along the beam. In the 296 HV materials exhibiting cyclic softening, the plastic strain region does not grow but rather remains constant throughout 100 cycles (Fig. 14). Cyclic material softening causes the maximum stress region to narrow, even greater is the decrease of maximum von Mises stresses in the region in which the material is subject to cyclic plasticity.

\section{CONCLUSIONS}

The influences of the YPP on cyclic plasticity of the console beam have been under-researched through experimental observations and numerical simulations. Numerical results for the model with the YPP and model without the YPP formulation were compared with experimental results. The specimens were made from EN 42 CrMo 4 steel in its normalized (184 HV) and tempered hardness values (296 HV) with the purpose to analyse the influence of the YPP in relation to cyclic hardening and softening.

Results such as force vs. displacement, force vs. cycle numbers as well as comparison of strain and stress field of a console beam were presented. Based on the presented results, it is evident that formulation of the YPP in the constitutive models of cyclic plasticity leads to better correlation with experimental 
results in all presented cases. Comparison of von Mises stress results for the model with the YPP and without the YPP allows the reader to understand the real significance of the YPP effect on cyclic plasticity. Based on the presented results, it is evident that formulation of the YPP in constitutive models of cyclic plasticity leads to more realistic forecasts of the stress-strain response during cyclic plasticity.

\section{REFERENCES}

[1] Cottrell, A.H., Bilby, B.A. (1949). Dislocation theory of yielding and strain ageing in iron. Proceedings of Physics Society A, vol. 62, no. 1, p. 49-62, Dol:10.1088/0370-1298/62/1/308.

[2] Hall, E.O. (1970). Yield Point Phenomena in Metals and Alloys. Plenum Press, New York, DOI:10.1007/978-1-4684-1860-6.

[3] Franciosi, P., Le, L.T., Monnet, G., Kahloun, C., Chavanne, M.H. (2015). Investigation of slip system activity in iron at room temperature by SEM and AFM in-situ tensile and compression tests of iron single crystals. International Journal of Plasticity, vol. 65, p. 226-249, D0l:10.1016/j.jplas.2014.09.008.

[4] Tsuchida, N., Masuda, H., Harada, Y., Fukaura, K., Tomota, Y., Nagai, K. (2008). Effect of ferrite grain size on tensile deformation behavior of a ferrite-cementite low carbon steel. Materials Science and Engineering: A, vol. 488, no. 1-2, p. 446-452, DOI:10.1016/j.msea.2007.11.047.

[5] Zhang, J., Jiang, Y. (2005). Lüders bands propagation of 1045 steel under multiaxial stress state. International Journal of Plasticity, vol. 21, no. 3, p. 651-670, D0l:10.1016/j. ijplas.2004.05.001.

[6] Bechle, N.J., Kyriakides, S(2014). Localization in NiTi tubes under bending. International Journal of Solids and Structures, vol. 51, no. 5, p. 967-980, DOl:10.1016/j.jijsolstr.2013.11.023.

[7] Tsuji, N., Ito, Y., Saito, Y., Minamino, Y. (2002). Strength and ductility of ultrafine grained aluminum and iron produced by ARB and annealing. Scripta Materialia, vol. 47, no. 12, p. 893899, DOI:10.1016/S1359-6462(02)00282-8.

[8] Mahmudi, R. (1994). Yield point phenomenon in ultrafinegrained aluminium sheets. Materials Letters, vol. 19, no. 5-6, p. 243-246, DOl:10.1016/0167-577X(94)90164-3.

[9] Colas, D., Finot, E., Flouriot, S., Forest, S., Mazière, M., Paris, T. (2014). Investigation and modeling of the anomalous yield point phenomenon in pure tantalum. Materials Science and Engineering: A, vol. 615, p. 283-295, D0l:10.1016/j. msea.2014.07.028.

[10] Knezevic, M., Beyerlein, I.J., Lovato, M.L., Tomé, C.N., Richards, A.W., McCabe, R.J. (2014). A strain-rate and temperature dependent constitutive model for BCC metals incorporating non-Schmid effects: Application to tantalum-tungsten alloys. International Journal of Plasticity, vol. 62, p. 93-104, DOI:10.1016/j.jplas.2014.07.007.

[11] Dickson, J.l., Sayar, A. (1977). The influence of aging stress on the yield point phenomenon in the zirconium alloy, ozhennite 0.5. Journal of Nuclear Materials, vol. 64, no. 1-2, p. 49-56, DOI:10.1016/0022-3115(77)90007-1.

[12] González-Doncel, G., Adeva, P., Cristina, M.C., Ibá-ez, J. (1995). Lüders bands formation in a rapidly solidified $\mathrm{Ni}_{3} \mathrm{Al}$ alloy ribbon. Acta Metallurgica et Materialia, vol. 43, no. 12, p. 4281-4287, Dol:10.1016/0956-7151(95)00140-Q.

[13] Min, J., Hector, Jr. L.G., Lin, J., Carter, J.T., Sachdev, A.K. (2014). Spatio-temporal characteristics of propagative plastic instabilities in a rare earth containing magnesium alloy. International Journal of Plasticity, vol. 57, p. 52-76, D0I:10.1016/j.ijplas.2014.02.004.

[14] Barnett, M.R., Nave, M.D., Ghaderi, A. (2012). Yield point elongation due to twinning in a magnesium alloy. Acta Materialia, vol. 60, no. 4, p. 1433-1443, Dol:10.1016/j. actamat.2011.11.022.

[15] Hallai, J.F., Kyriakides, S. (2013). Underlying material response for Lüders-like instabilities. International Journal of Plasticity, vol. 47, p. 1-12, Dol:10.1016/j.ijplas.2012.12.002.

[16] Khan, T., Rabinovitch, M., Stohr, J.F., Trottier, J.P., Bibring, H. (1973). On the yield point phenomenon in composites. Scripta Metallurgica, vol. 7, no. 7, p. 727-730, Dol:10.1016/00369748(73)90122-1.

[17] Lu, J., Ravi-Chandar, K. (1999). Inelastic deformation and localization in polycarbonate under tension. International Journal of Solids and Structures, vol. 36, no. 3, p. 391-425, DOI:10.1016/S0020-7683(98)00004-3.

[18] Wu, T., Cao, Y., Yang, F., Xiang, M. (2014). Investigation on double yielding behavior under tensile loading in isotactic polypropylene. Materials \& Design, vol. 60, p. 153-163, Dol:10.1016/j.matdes.2014.03.044.

[19] Burg, J.P., Harris, L.B. (1982). Tension fractures and boudinage oblique to the maximum extension direction: an analogy with lüders' bands. Tectonophysics, vol. 83, no. 3-4, p. 347-363, DOI:10.1016/0040-1951(82)90027-0.

[20] Watterson, J. (1999). The future of failure: stress or strain? Journal of Structural Geology, vol. 21, no. 8-9, p. 939-948, DOI:10.1016/S0191-8141(99)00012-7.

[21] Schwab, R., Ruff, V. (2013). On the nature of the yield point phenomenon. Acta Materialia, vol. 61, no. 5, p. 1798-1808, D0I:10.1016/j.actamat.2012.12.003.

[22] Wenman, M.R., Chard-Tuckey, P.R. (2010). Modelling and experimental characterisation of the Lüders strain in complex loaded ferritic steel compact tension specimens. International Journal of Plasticity, vol. 26, no. 7, p. 10131028, DOI:10.1016/j.jijplas.2009.12.005.

[23] Aguirre, F., Kyriakides, S., Yun, H.D. (2004). Bending of steel tubes with Lüders bands. International Journal of Plasticity, vol. 20, no. 7, p. 1199-1225, D0l:10.1016/j.ijplas.2003.05.001.

[24] Hallai, J.F., Kyriakides, S. (2011). On the effect of Lüders bands on the bending of steel tubes. Part I: Experiments. International Journal of Solids and Structures, vol. 48, no. 24, p. 3275-3284, D0I:10.1016/j.ijsolstr.2011.06.024.

[25] Zou, T., Li, D., Wu, G., Peng, Y. (2016). Yield strength development from high strength steel plate to UOE pipe. Materials \& Design, vol. 89, p. 1107-1122, D0l:10.1016/j. matdes.2015.10.095.

[26] Žerovnik, A., Pepel, V., Prebil, I., Kunc, R. (2016). The yieldpoint phenomenon and cyclic plasticity of the uniaxially loaded specimens. Materials \& Design, vol. 92, p. 971-977, Dol:10.1016/j.matdes.2015.12.111.

[27] Hahn, G.T. (1962). A model for yielding with special reference to the yield-point phenomena of iron and related 
bcc metals. Acta Metallurgica, vol. 10, no. 8, p. 727-738, DOI:10.1016/0001-6160(62)90041-X.

[28] Johnston, W.G., Gilman, J.L. (1959). Dislocation velocities, dislocantion densities and plastic flow in lithium floride crystals. Journal of Applied Physics, vol. 30, no. 2, p. 129, D0I:10.1063/1.1735121.

[29] Shioya, T., Shioiri, J. (1976). Elastic-plastic analysis of the yield process in mild steel. Journal of the Mechanics and Physics of Solids, vol. 24, no. 4, p. 187-204, D0l:10.1016/00225096(76)90002-8.

[30] Itoh, M., Yoshida, F., Yamashita, Y., Ohmori. M. (1992). FEM Analysis for Nonuniform Yielding Processes in Mild Steel Plates under Stretching. JSME International Journal Ser. 1, Solid Mechanics, Strength of Materials, vol. 35, no. 1, p. 7077, D0l:10.1299/jsmea1988.35.1_70.

[31] Armstrong, P.J., Frederick, C.0. (1966). A Mathematical Representation of the Multiaxial Bauschinger Effect. Central Electricity Generating Board, Berkeley Nuclear Laboratories, Berkley.

[32] Chaboche, J.L., Gaubert, A., Kanouté, P., Longuet, A., Azzouz, F., Mazière, M. (2013). Viscoplastic constitutive equations of combustion chamber materials including cyclic hardening and dynamic strain aging. International Journal of Plasticity, vol. 46, p. 1-22, D0l:10.1016/j.jplas.2012.09.011.

[33] Chaboche, J.L. (1986). Time-independent constitutive theories for cyclic plasticity. International Journal of Plasticity, vol. 2, no. 2, p. 149-188, D0l:10.1016/0749-6419(86)90010-0.

[34] Chaboche, J.L. (1989). Constitutive equations for cyclic plasticity and cyclic viscoplasticity. International Journal of Plasticity, vol. 5, no. 3, p. 247-302, D0l:10.1016/07496419(89)90015-6.

[35] Abdel-Karim, M., Ohno, N. (2000). Kinematic hardening model suitable for ratchetting with steady-state. International Journal of Plasticity, vol. 16, no. 3-4, p. 225-240, D0l:10.1016/S07496419(99)00052-2.

[36] Abdel-Karim, M., Khan, A. (2010). Cyclic multiaxial and shear finite deformation responses of OFHC Cu. Part II: An extension to the $\mathrm{KHL}$ model and simulations. International Journal of Plasticity, vol. 26, no. 5, p. 758-773, D0l:10.1016/j. ijplas.2009.10.008.

[37] Abdel-Karim, M. (2009). Modified kinematic hardening rules for simulations of ratchetting. International Journal of Plasticity, vol. 25, no. 8, p. 1560-1587, D0l:10.1016/j. ijplas.2008.10.004.

[38] Abdel-Karim, M. (2010). An evaluation for several kinematic hardening rules on prediction of multiaxial stress-controlled ratchetting. International Journal of Plasticity, vol. 26, no. 5, p. 711-730, D0I:10.1016/j.ijplas.2009.10.002.

[39] Abdel-Karim, M. (2010). An extension for the Ohno-Wang kinematic hardening rules to incorporate isotropic hardening. International Journal of Pressure Vessels and Piping, vol. 87, no. 4, p. 170-176, D0l:10.1016/j.ijpvp.2010.02.003.

[40] Yu, D., Chen, G., Yu, W., Li, D., Chen, X. (2012). Visco-plastic constitutive modeling on Ohno-Wang kinematic hardening rule for uniaxial ratcheting behavior of Z2CND18.12N steel. International Journal of Plasticity, vol. 28, no. 1, p. 88-101, DOI:10.1016/j.ijplas.2011.06.001.
[41] Pham, M.-S., ladicola, M., Creuziger, A., Hu, L., Rollett, A.D. (2015). Thermally-activated constitutive model including dislocation interactions, aging and recovery for strain path dependence of solid solution strengthened alloys: Application to AA5754-0. International Journal of Plasticity, vol 75, p. 226243, D0I:10.1016/j.ijplas.2014.09.010.

[42] Chaboche, J.L. (2008). A review of some plasticity and viscoplasticity constitutive theories. International Journal of Plasticity, vol. 24, no. 10, p. 1642-1693, D0l:10.1016/j. ijplas.2008.03.009.

[43] Ohno, N., Wang, J.D. (1993). Kinematic hardening rules with critical state of dynamic recovery, part I: formulation and basic features for ratchetting behavior. International Journal of Plasticity, vol. 9, no. 3, p. 375-390, D0l:10.1016/07496419(93)90042-0.

[44] Ohno, N., Wang, J.D. (1993). Kinematic hardening rules with critical state of dynamic recovery, part II: Application to experiments of ratchetting behavior. International Journal of Plasticity, vol. 9, no. 3, p. 391-403, D0l:10.1016/07496419(93)90043-P.

[45] Korelc, J., Skuber, P., Beg, D. (2004). Derivation of Finite Strain Damage Model for Simulation of Low-Cycle Fatigue of Steel Structures. Computational Mechanics. Tsinghua University Press, Beijing, p. 264.

[46] Žerovnik, A., Kunc, R., Prebil, I. (2010). Yield-point phenomenon in constitutive models of cyclic plasticity. Computational Materials Science, vol. 49, no. 3, p. 473-482, D0I:10.1016/j.commatsci.2010.05.038.

[47] Yoshida, F., Kaneda, Y., Yamamoto, S. (2008). A plasticity model describing yield-point phenomena of steels and its application to FE simulation of temper rolling. International Journal of Plasticity, vol. 24, no. 10, p. 1792-1818, D0I:10.1016/j.ijplas.2008.05.004.

[48] Yoshida, F. (2000). A constitutive model of cyclic plasticity. International Journal of Plasticity, vol. 16, no. 3-4, p. 359-380, D0l:10.1016/S0749-6419(99)00058-3.

[49] Kunc, R., Zerovnik, A., Prebil, I. (2007). Verification of numerical determination of carrying capacity of large rolling bearings with hardened raceway. International Journal of Fatigue, vol. 29, no. 9-11, p. 1913-1919, D0l:10.1016/j. ijfatigue.2007.02.003.

[50] Krishna, S., Hassan, T., Ben Naceur, I., Saï, K., Cailletaud, G. (2009). Macro versus micro-scale constitutive models in simulating proportional and nonproportional cyclic and ratcheting responses of stainless steel 304. International Journal of Plasticity, vol. 25, no. 10, p. 1910-1949, D0l:10.1016/j.ijplas.2008.12.009.

[51] Franulovic, M., Basan, R., Prebil, I. (2009). Genetic algorithm in material model parameters' identification for low-cycle fatigue. Computational Materials Science, vol. 45, no. 2, p. 505-510, D0I:10.1016/j.commatsci.2008.11.012.

[52] Instron (2008). Instron 8800 Servohydraulic Testing Systems. Instron, Norwood.

[53] Korelc, J. (1997). Automatic generation of finite-element code by simultaneous optimization of expressions. Theoretical Computer Science, p. 187, no. 1-2, p. 231-248, D0l:10.1016/ S0304-3975(97)00067-4. 